\title{
Proprioception Recovery After Anterior Cruciate Ligament Reconstruction - Isokinetic Versus Dynamic Exercises
}

\author{
Dragana Dragičević-Cvjetković,, 2 Tatjana Erceg-Rukavina, ${ }^{1}$ Siniša Nikolić ${ }^{1}$
}

\section{Abstract}

Background / Aim: Proprioception recovery is one of the main postoperative rehabilitation goals after the anterior cruciate ligament (ACL) reconstruction. The aim of this study was to examine the level of proprioception recovery in patients 9 months after the ACL reconstruction using hamstring graft.

Methods: A prospective study followed 70 male subjects (mean age $27.36 \pm$ 5.94) divided into two groups depending on the type of proprioceptive exercise applied. Group A patients $(n=35)$ underwent proprioceptive training on a Biodex 4 Pro System isokinetic dynamometer for 10 minutes 5 times per week. In group B, patients underwent proprioception exercises in the gym for 10 minutes 5 times per week. The degree of recovery of proprioception was measured on an isokinetic dynamometer preoperatively and 9 months after ACL reconstruction. Flexion angles in the operated knee of 15, 30 and 45 degrees were monitored. The Chi-square test was used for statistical analyses. The value of $\mathrm{p}<0.05$ was considered significant.

Results: A significant difference was found in the recovery of proprioception in patients depending on the type of training applied. Statistically significant recovery of proprioception was observed in patients from both groups 9 months after ACL reconstruction, but it was better in patients of group $A(p<0.05)$.

Conclusion: Applying proprioceptive training on an isokinetic dynamometer achieves better proprioceptive recovery in patients 9 months after ACL reconstruction versus dynamic exercises in the gym.

Key words: Proprioception; Rehabilitation; Anterior cruciate ligament reconstruction.
(1) Institute of Physical Medicine and Rehabilitation "Dr Miroslav Zotović" Banja Luka, the Republic of Srpska, Bosnia and Herzegovina.

(2) Faculty of Medicine, University of Banja Luka, the Republic of Srpska, Bosnia and Herzegovina.

Correspondence:

DRAGANA

DRAGIČEVIĆ-CVJETKOVIĆ

E: dragicevicdr@gmail.com

M: +387 65711138

\section{ARTICLE INFO}

Received: 5 December 2021

Revision received: 7 December 2021 Accepted: 7 December 2021

\section{Introduction}

Proprioception is one of the key elements in the complex process of maintaining balance. ${ }^{1}$ Having in mind the histological structure of the anterior cruciate ligament (ACL), it is clear that its rupture leads to damage of fast and slow mechanoreceptors and consequently, to damage of proprioception. ${ }^{2}$ Surgical treatment of patients after the anterior cruciate ligament reconstruction restores static stability, but achieving dynamic stability is the task of postoperative rehabilitation. If the restoration of proprioception is not achieved, the patient is at risk of re-injuries to the structures of the operated but also injuries of the contralateral knee. ${ }^{3}$ During the postoperative rehabilitation of patients after ACL reconstruction proprioceptive re-education exercises are one of the constituent elements of the rehabilitation protocol. Proprioception training is conducted in all phases of postoperative rehabilitation in these patients, but the emphasis on this segment is given from the third postoperative month until its completion. There are different types of proprioceptive 
training. When choosing them, the rule from simpler to more complex is followed, exercises in closed and open kinetic chain, dynamic and isokinetic. ${ }^{4}$ The state of proprioception can be evaluated by various methods. ${ }^{5,6}$ Measurement of an isokinetic system is one of the objective ways to assess its recovery. ${ }^{7}$

In this study, the degree of proprioception recovery was investigated in patients 9 months after ACL reconstruction with a hamstring graft using two types of therapeutic exercises, isokinetic and dynamic.

\section{Methods}

This prospective clinical study comprised a total of 70 recreational athletes, men, divided into two groups depending on the type of proprioceptive exercise applied during rehabilitation after arthroscopic ACL reconstruction with a hamstring graft. All patients were operated by the same surgical team, all had unilateral, isolated ACL rupture; all were operated on in the phase of chronic ACL insufficiency with the same surgical technique and were of the same level of physical activity (football players, recreational athletes who performed sports activities twice a week for 90 minutes). Non-inclusion criteria were: female gender, joint injuries of other structures of the same knee or injuries and operations on the contralateral knee and injuries and surgical interventions on other ankles. Postoperative rehabilitation in the first three months was performed without differences in the type of therapeutic exercises of proprioceptive re-education. After three months from the operation, all patients were evaluated for neuromuscular performance on the Biodex 4 Pro System isokinetic dynamometer in order to be prescribed with targeted exercises to increase the muscle strength, endurance and proprioception. Patients were then divided into two groups (group A and group B) according to the available type of proprioceptive exercise determined by the place of residence. Group A patients $(\mathrm{n}=35)$ underwent proprioceptive training on a Biodex 4 Pro System isokinetic dynamometer for 10 minutes 5 times per week. In group B, patients underwent proprioception exercises in the gym for 10 minutes 5 times per week. These patients performed the above type of therapeutic exercises at the Department of Physical Medicine and Rehabilitation "Dr Miroslav Zotović" Banja
Luka, which is only public health institution in the Republic of Srpska that has the isokinetic system.

After a six-minute warm-up on a stationary bike, all patients began performing isokinetic exercises to strengthen the quadriceps and hamstrings of the operated leg for 20 minutes. They then continued with proprioception exercises for 10 minutes. The starting position for conducting proprioceptive re-education exercises was a sitting position on a dynamometer chair with the torso, upper leg and a lower leg fixed with stabilisation straps for the chair back and for dynamometer extensions. The torso was placed at an angle of $90^{\circ}$ in relation to the upper leg, as well as the upper leg in relation to the lower leg. The lower leg was fixed with stabilisation straps to continue the dynamometer in the area of the fibula head and $3 \mathrm{~cm}$ above the malleolus. The range of motion in the knee was from $0-90^{\circ}(0$ represented the initial position full extension in the knee and the final position is flexion in the knee of $\left.90^{\circ}\right) .{ }^{8}$ The patient was then asked to first recognise and keep the lower leg at the indicated flexion angles with his eyes open and then closed. In group B, patients performed proprioception exercises for 10 minutes 5 times a week during the rehabilitation treatment at the gym in the basic rehabilitation centres (CBRs) in place of residence. Proprioceptive training in these patients consisted of exercises on unstable surfaces (balls, balance plates and balancers). Exercise on the isokinetic system was not available due to the lack of equipment of local CBRs for this technology. Recovery of proprioception was measured on an isokinetic dynamometer 3 and 9 months after ACL reconstruction. Recognition of flexion angles in the operated knee of $15^{\circ}, 30^{\circ}$ and $45^{\circ}$ were monitored. The Chi-square test was used for statistical analyses. The value of $\mathrm{p}<0.05$ was considered significant.

\section{Results}

The sample consisted of 70 men, recreational athletes, with an average age of $27.36 \pm 5.36$ years (Table 1).

Significant recovery of proprioception was observed 9 months after ACL reconstruction in patients from both study groups, but its recovery was statistically significantly better in patients from the group A (Figure 1). 
Table 1: Demographic characteristics of patients by groups

\begin{tabular}{ccccc}
\hline Group & $\begin{array}{c}\text { Number of } \\
\text { patients }\end{array}$ & $\begin{array}{c}\text { Age } \\
\text { (Mean } \pm \text { SD) }\end{array}$ & $\begin{array}{c}\text { Sport-specific activity (football) } \\
\text { (\% of total sample) }\end{array}$ & $\begin{array}{c}\text { Sport level /recreatives } \\
\text { (\% of total sample) }\end{array}$ \\
\hline Group A & 35 & $26.31 \pm 4.72$ & 100 & 100 \\
\hline Group B & 35 & $28.42 \pm 6.01$ & 100 & 100 \\
\hline
\end{tabular}

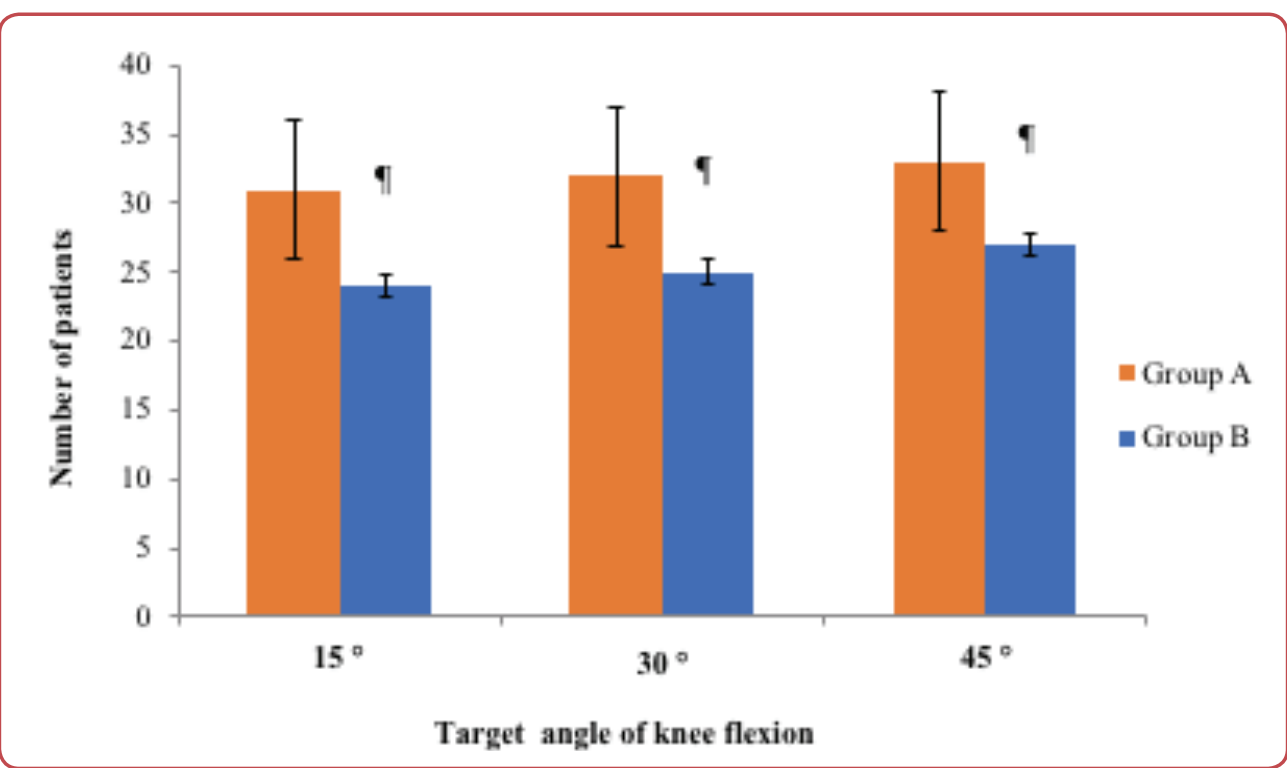

Figure 1: Differences in achieving target knee flexion angles on isokinetic testing in patients 9 months after anterior cruicate ligament (ACL) reconstruction using hamstrings graft between patients in Group $A$ and Group B. Isokinetic vs dynamic proprioception exercises.

If $p<0.05$

\section{Discussion}

Proprioception is a feeling for the position of one part of the body in relation to others and the ability to detect movement in the joint (kinaesthesia). It is an important part of the somatosensory nervous system. ${ }^{9}$ The ACL is known to contain mechanoreceptors, including Golgi tendon organs, Pacinian corpuscles and Ruffini nerve endings. ${ }^{10}$ These receptors form part of the reflex arc in which anterior tibial translation results in contraction of the muscles of the posterior tibial lobe representing the protective mechanism. This contraction occurs at the level of the reflex arc. Therefore, it can be expected that the rupture of the ACL will lead to the rupture of the reflex arc because the rupture had eliminated the first element of the reflex arc, the receptor. ${ }^{11}$

Modern rehabilitation protocols cannot be imagined without the element of proprioceptive training as one of the key elements of the restoration of the dynamic stability of the knee after ligamentoplasty of the ACL. Many authors have monitored the recovery of proprioception in patients after ACL reconstruction. ${ }^{12-18}$ The speed of recovery was determined, among other things, by the type of proprioceptive re-education exercises used. However, the different results regarding the recovery time of proprioception in these patients can be explained by differences in the characteristics of the examined sample in terms of age, sex and level of physical activity. It also depends on: the type of surgical technique applied, the time that elapsed from the injury to the operation, the period of monitoring the patient, different methods of measuring the degree of recovery. ${ }^{19}$ There were also studies that compared the level of proprioception of operated patients in different postoperative periods in comparison to healthy subjects. ${ }^{20}$

Kinesitherapy is a basic component of postoperative rehabilitation protocols in patients after ACL reconstruction. A therapeutic exercise or kinesitherapy program is a physical activity prescribed on the basis of evidence-based medicine with the 
goal of restoring or altering a specific function in a joint, muscle, or kinetic chain created after an injury. These specific functions can be increasing the range of motion in the joint, strengthening muscle strength, increasing muscle endurance and improving neuromuscular control. ${ }^{21,22}$ Isokinetic exercises primarily belong to the dynamic type of exercise during which movement occurs in the joint or part of the body. Isokinetic exercise means that it is performed at constant speed (ranging from 1 / sec to 1000 / sec) with variable resistance. Variable resistance means that this is the only way of exercising during which the muscle can be maximally loaded through the entire range of motion. This is of particular importance because it avoids fatigue and overload, which represents absolute safety for the patient as he is never exposed to resistance that he cannot overcome. The isokinetic exercise contains three main components: acceleration, deceleration and load range. ${ }^{23}$

It is clear that during these exercises, especially when it comes to acceleration and deceleration, in addition to muscle strengthening exercises, patient also conducts targeted proprioceptive training. Proprioceptive re-education exercises include a competent feedback mechanism of audio-visual signals that provide the patient with information regarding the confirmation or failure of the target flexion angle in the examined knee. Thus, the application of proprioceptive re-education exercises on the isokinetic system also includes the vestibular, sensory and motor mechanisms needed to maintain body balance. This could be one of the reasons for better recovery of proprioception in patients from group A. On the other hand, patients from group B conducted a kinesitherapy program based on static and dynamic exercises to strengthen the thigh muscles with variable speed and different loads. The challenges of this exercise are overload, faster fatigue and the occurrence of reflex quadriceps inhibition during which proprioceptive training is absolutely useless because the central sensory control mechanisms in this situation do not receive information about the condition of the joint and/or body on the periphery. This results in the absence of motor control of the thigh muscles, which significantly affects the recovery of proprioception. ${ }^{24}$ It is probable that with the advancement of technology in the future it can be expected that the appearance of isokinetic systems that will be able to measure the parameters of proprioceptive recovery after ligamentoplasty of the ACL of the knee with great sensitivity and specificity. It is also to be hoped that the quality of patient rehabilitation after ACL reconstruction in the CBRs in the Republic of Srpska and Bosnia and Herzegovina will improve in the future through improved infrastructural conditions, equipment supply and staff education.

\section{Conclusion}

Proprioceptive training on the isokinetic system gives better recovery of patients. The recovery is achieved 9 months after ACL reconstruction using a hamstring graft compared to dynamic proprioception exercises. These encouraging initial results need to be confirmed on a larger sample and over a longer follow-up period.

\section{Acknowledgements}

None.

\section{Conflict of interest}

None.

\section{References}

1. Allum JH, Bloem BR, Carpenter MG, Hulliger M, Hadders-Algra M. Proprioceptive control of posture: a review of new concepts. Gait Posture 1998 Dec;8(3):21442.

2. Sherrington CS. On the proprioceptive system, especially its reflex aspect. Brain 1907;29:467-82.

3. Dietz V. Proprioception and locomotor disorders. Nat Rev Neurosci 2002 Oct;3(10):781-90.

4. Ashton-Miller JA, Wojtys EM, Huston LJ, Fry-Welch D. Can proprioception really be improved by exercises? Knee Surg Sports Traumatol Arthrosc 2001 May;9(3):128-36.

5. Buckthorpe M, Della Villa F. Optimising the 'mid-stage' training and testing process after ACL reconstruction. Sports Med 2020 Apr;50(4):657-78.

6. Bączkowicz D, Skomudek A. Assessment of neuromuscular control in patients after anterior cruciate ligament reconstruction. Ortop Traumatol Rehabil 2013;15(3):205-14. 
7. Dragičević-Cvjetkovic D, Bijeljac S, Palija S, Talić G, Nožica Radulović T, Kosanović Glogovac M, et al. Isokinetic testing in evaluation rehabilitation outcome after ACL reconstruction. Med Arch 2015;69(1):21-3.

8. Feiring CD, Ellenbecker ST, Derscheid LG. Test-retest reliability of the Biodex isokinetic dynamometer. J Orthop Sports Phys Ther 1990;11(7):298-300.

9. Czamara A, Tomaszewski W, Bober T, Lunarski B. The effect of physiotherapy on knee joint extensor and flexor muscle strength after anterior cruciate ligament reconstruction using hamstring tendon. Med Sci Monit 2011;17(1):33-41.

10. Briggs K, Lysholm J, Tegner Y, Rodkey W, Kocher M, Steadman R. The reliability, validity and responsiveness of the Lysholm score and Tegner activity scale for anterior cruciate ligament injuries of the knee: 25 years later. Am J Sports Med 2009;37(5):890-7.

11. Rossignol S, Dubuc R, Gossard JP. Dynamic sensorimotor interactions in locomotion. Physiol Rev 2006 Jan;86(1):89-154.

12. Filbay SR, Ackerman IN, Russell TG, Crossley KM. Factors related to quality of life in people with knee pain, stiffness or activity limitations 5 to 20 years following anterior cruciate ligament reconstruction. Osteoarthritis Cartilage 2015;23(2):A279-80.

13. Hunnicutt J, McLeod M, Slone S, Gregory C. Quadriceps neuromuscular and physical function after anterior cruciate ligament reconstruction. J Athl Train 2020;55(3):238-45.

14. Liu-Ambrose T, Taunton JE, MacIntyre D, McConkey P, Khan KM. The effects of proprioceptive or strength training on the neuromuscular function of the ACL reconstructed knee: a randomized clinical trial. Scand J Med Sci Sports 2003 Apr;13(2):115-23..

15. Chouteau J, Testa R, Viste A, Moyen B. Knee rotational laxity and proprioceptive function 2 years after partial ACL reconstruction. Knee Surg Sports Traumatol Arthrosc 2012;20(4):762-6.

16. Risberg MA, Holm I, Steen H, Beynnon BD. Sensitivity to changes over time for the IKDC form, the Lysholm score and the Cincinnati knee score. A prospective study of
120 ACL reconstructed patients with a 2-year follow-up. Knee Surg Sports Traumatol Arthrosc 1999;7(3):152-9.

17. Arundale AJH, Cummer K, Capin JJ, Zarzycki R, Snyder-Mackler L. Report of the clinical and functional primary outcomes in men of the ACL-SPORTS Trial: Similar outcomes in men receiving secondary prevention with and without perturbation training 1 and 2 years after AVL reconstruction. Clin Orthop Relat Res 2017 Oct;475(10):2523-34.

18. Guney-Deniz H, Harput G, Kaya D, Nyland J, Doral MN. Quadriceps tendon autograft ACL reconstructed subjects overshoot target knee extension angle during active proprioception testing. Knee Surg Sports Traumatol Arthrosc 2020 Feb;28(2):645-52.

19. Johnson RJ, Eriksson E, Haggmark T, Pope MH. Five-to ten-year follow-up evaluation after reconstruction of the anterior cruciate ligament. Clin Orthop Relat Res 1984 Mar;(183):122-40.

20. Dubljanin-Raspopović E, Kadija M, Matanović D. [Evaluation of the intensive rehabilitation protocol after arthroscopically assisted anterior cruciate ligament reconstruction]. Srp Arh Celok Lek 2006 NovDec;134(11-12):532-6. Serbian.

21. Risberg MA, Holm I, Myklebust G, Engebretsen L. Neuromuscular training versus strength training during first 6 months after anterior cruciate ligament reconstruction: a randomized clinical trial. Phys Ther 2007;87(6):737-50.

22. Tsaklis P, Abatzides G. ACL rehabilitation program using a combined isokinetic and isotonic strengthening protocol. Isokinet Exerc Sci 2002;10(4):211-9.

23. Lin DH, Lin YF, Chai HM, Han YC, Jan M. Comparison of proprioceptive functions between computerized proprioception facilitation exercise and closed kinetic chain exercise in patients with knee osteoarthritis. Clin Rheumatol 2007;26(4):520-8.

24. Ju YY, Wang CW, Cheng HY. Effects of active fatiguing movement versus passive repetitive movement on knee proprioception. Clin Biomech (Bristol, Avon) 2010 Aug;25(7):708-12. 